\title{
Evaluación de la producción y calidad nutritiva de avena como forraje verde hidropónico en condiciones de desierto
}

\author{
Assessment of production and nutritious quality of oats as green \\ hydroponic fodder under desert conditions \\ Francisco Fuentes $^{1 *}$, Cecilia Poblete ${ }^{1}$, Manuel Huerta ${ }^{1}$, Inés Palape ${ }^{2}$
}

\begin{abstract}
RESUMEN
Los parámetros productivos y nutritivos de avena (Avena sativa) como forraje verde hidropónico (FVH) se evaluaron a través de tres ensayos en condiciones de desierto en el sector Pampa del Tamarugal, Chile. En el primer ensayo se evaluaron cuatro tiempos de remojo de semillas $(0,12,24$ y $48 \mathrm{~h})$, midiendo porcentaje de germinación y tasa media de germinación. El mejor tratamiento fue el remojo por $12 \mathrm{~h}$. El segundo ensayo evaluó diferentes dosis de semilla $\left(1,6 ; 3,2 ; 4,8\right.$ y $\left.6,4 \mathrm{~kg} \mathrm{~m}^{-2}\right)$, midiendo porcentaje de plantas normales 10 días después de la siembra (DDS). La mejor dosis correspondió a $6,4 \mathrm{~kg} \mathrm{~m}^{-2}$, presentando el máximo valor de plantas normales. El tercer ensayo evaluó cuatro tiempos de cosecha (7, 10, 13 y 16 DDS), midiendo los parámetros de altura de planta, conversión (materia seca de forraje por materia seca de semillas) y análisis químico del material cosechado. El día 10 fue el mejor tiempo de cosecha, caracterizado por presentar 36,86\% materia seca, 14,79\% proteína bruta, 18,77\% fibra cruda y una mejor condición sanitaria de forraje. A partir de los resultados obtenidos se pudieron establecer los parámetros productivos y nutritivos básicos para el cultivo de avena como FVH en condiciones de desierto.
\end{abstract}

Palabras clave: Forraje verde hidropónico, avena, Pampa del Tamarugal, tiempo de remojo de semillas, dosis de semilla, tiempo de cosecha.

\begin{abstract}
Productive and nutrition parameters of oats grown as green hydroponic fodder were assessed by three assays under desert conditions in the "Pampa del Tamarugal" area of northern Chile. The first assay assessed four seed soaking times (0, 12, 24 and 48 hours). The variables measured were percentage and mean rate of germination. The best treatment was 12 hours of seed soaking. The second assay assessed different seed doses $\left(1.6,3.2,4.8\right.$, and $\left.6.4 \mathrm{~kg} \mathrm{~m}^{-2}\right)$. The variable measured was the percentage of normal plants 10 days after sowing. The best seed dose was $6.4 \mathrm{~kg} \mathrm{~m}^{-2}$, which had the greatest value of normal plants. The third assay tested four harvest times (7, 10,13 and 16 days after sowing); the traits measured were plant height, conversion (dry matter of forage per dry matter of seeds) and chemical analysis of harvested material. The tenth day was the best harvest time, which contained $36.86 \%$ dry matter, $14.79 \%$ crude protein, $18.77 \%$ fiber and better sanitary conditions of forage. The results obtained in this study allowed the establishment of the basic parameters of production and nutrition quality for oats grown as green hydroponic fodder under desert conditions.
\end{abstract}

Key words: Green hydroponic fodder, oats, Pampa del Tamarugal, seed soaking time, seed dose, harvest time.

\section{Introducción}

Uno de los desafíos importantes que enfrenta la agricultura en el norte de Chile es disponer de forraje en cantidad y calidad estable para la alimentación del ganado. Esta condición se ve limitada a causa de las restricciones climáticas y edáficas que impone la condición de aridez del desierto de
Atacama (Fuentes, 2009). Pese a esto, el sector denominado Pampa del Tamarugal presenta una importante fuente de vegetación para el ganado: el tamarugo (Prosopis tamarugo) (Riveros, 1991).

En este lugar un número creciente de comunidades rurales ha explotado los bosques de tamarugo con diversos propósitos: forraje, madera y leña (Habit, 1981), provocando un acelerado proceso de deterioro

1 Departamento de Agricultura del Desierto y Biotecnología, Universidad Arturo Prat. Avda. Arturo Prat 2120, Campus Huayquique, Iquique, Chile.

2 Departamento de Ciencias Químicas y Farmacéuticas. Universidad Arturo Prat, Casilla 121, Iquique, Chile.

* Autor responsable: Francisco F. Fuentes. Universidad Arturo Prat, Departamento de Agricultura del Desierto y Biotecnología, Iquique, Chile; Tel.: +56 57 394505; fax: +56 57 445190. E-mail: francfue@ unap.cl

Fecha de Recepción: 27 Septiembre, 2010.

Fecha de Aceptación: 26 Enero, 2011. 
de este recurso forrajero (Torres, 1989; Carevic, 2000), el cual es agudizado en la actualidad por la intensiva extracción de agua subterránea para uso urbano y actividades mineras (Rojas et al., 2009). Todo lo anterior hace crítica la disponibilidad de forraje a partir de este recurso natural para alrededor de 3.500 cabezas de ganado caprino-ovino existentes en el sector (INE, 2007).

Dada la situación restrictiva para el desarrollo de cultivos en la Pampa del Tamarugal, el sistema de producción de FVH representaría una alternativa de producción de forraje no-convencional. Sin embargo, no existe información disponible de evaluación de parámetros productivos y nutritivos en condiciones de desierto.

El sistema de FVH es una tecnología de producción de biomasa vegetal a partir de plántulas en estado de germinación y crecimiento temprano (FAO, 2001). Las especies comúnmente utilizadas en esta modalidad son avena, maíz, cebada, trigo y arroz (Resh, 2001).

Con el sistema hidropónico de producción de forrajes en base a cereales se han reportado ahorros entre $50 \%$ a $70 \%$ de agua en comparación a cultivos no hidropónicos (López et al., 2009). Asimismo una relación semilla/producción de 1 a $9 \mathrm{~kg}$ de forraje fresco (Bórquez et al., 1992; Müller, 2006).

$\mathrm{El}$ sistema de FVH puede proporcionar un suministro constante de alimento para el ganado durante épocas críticas de abastecimiento de forrajes (sequía/invierno), siendo apropiado para su producción pequeñas superficies de terrenos (Rodríguez et al., 2005; Espinoza et al., 2007). Por su parte, esta metodología ha sido incorporada en sistemas intensivos de producción animal para proporcionar un nuevo ingrediente como alimento, suplemento y/o reemplazo de uno o más componentes de la ración diaria (Figueroa et al., 1999; Rodríguez et al., 2005; Morales et al., 2009), debido a su alta palatabilidad, digestibilidad y por presentar en general niveles óptimos -según requerimiento animal- de energía, vitaminas y minerales (Chang et al., 2000).

El objetivo de la presente investigación fue evaluar los parámetros productivos y nutritivos básicos de avena como FVH en las condiciones de desierto en el norte de Chile.

\section{Materiales y Métodos}

La determinación de las características productivas de avena cv. Pepita Baer como FVH se realizó en la Estación Experimental Canchones de la Universidad Arturo Prat (latitud sur 20²6'34,2”; longitud oeste $69^{\circ} 32^{\prime} 7,9^{\prime \prime}$; altitud $1.005 \mathrm{msnm}$ ), entre los meses de noviembre del año 2006 y enero del 2007.

Para las evaluaciones se construyó un invernáculo rectangular de $35 \mathrm{~m}^{2}$ de superficie, construido de madera y alambre galvanizado, con cubierta de malla tipo Raschel blanca (60\% de sombra). Dentro del invernáculo se instaló un módulo de producción de FVH de madera de 4 pisos (1,6 m largo, 1,2 m ancho, $2 \mathrm{~m}$ alto) con capacidad de almacenamiento de 32 bandejas de zinc con drenaje basal $(50 \mathrm{~cm}$ largo, $40 \mathrm{~cm}$ ancho, $5 \mathrm{~cm}$ profundidad).

Previo a la siembra, las semillas de avena y bandejas fueron desinfectadas con solución de hipoclorito de sodio $2 \%$. Las semillas fueron sumergidas en solución desinfectante durante $10 \mathrm{~m}$ al final del proceso de remojo.

El riego fue realizado usando pulverizadora manual, con un promedio de $1 \mathrm{~L} \mathrm{~m}^{-2}$ cada $6 \mathrm{~h}$. $\mathrm{La}$ fertilización se realizó a través del agua de riego a partir de los 4 DDS hasta $2 \mathrm{~d}$ antes de la cosecha. La dosificación de nutrientes fue de 192,84 $\mathrm{mg} \mathrm{L}^{-1}$ de N, 24,9 mg L ${ }^{-1}$ de P, $190 \mathrm{mg} \mathrm{L}^{-1}$ de K, $100 \mathrm{mg}$ $\mathrm{L}^{-1}$ de Ca y $67 \mathrm{mg} \mathrm{L}^{-1}$ de $\mathrm{Mg}$ (Rodríguez, 2003).

En el primer ensayo de tiempo de remojo de semillas se establecieron cuatro tratamientos: 0 ( $\sin$ remojo previo), 12, 24 y 48 horas.

Después de $12 \mathrm{~h}$ del inicio de los tratamientos de 24 y $48 \mathrm{~h}$ el agua fue renovada, dejando airear las semillas durante $1 \mathrm{~h}$, reanudando posteriormente el remojo hasta completar el tiempo total de cada tratamiento cada $12 \mathrm{~h}$. El remojo fue realizado con agua de pozo disponible en la Estación Experimental Canchones.

En forma paralela se realizó prueba de germinación de las semillas de avena bajo condiciones controladas en cámara de germinación a $20{ }^{\circ} \mathrm{C}$ de temperatura durante $3 \mathrm{~d}$. Para ello se dispuso de 100 semillas por placa petri, empleando papel absorbente para mantener la humedad. La evaluación consideró 8 repeticiones.

Para todos los casos evaluados, se consideró como criterio de germinación la protrusión de la radícula a través del tegumento seminal (Salisbury y Ross, 2000).

Las variables medidas fueron porcentaje de germinación en un período de $7 \mathrm{~d}$ y tasa media de germinación según Hidalgo (1985), (Ecuación 1). 


$$
T M G=\sum_{t=1}^{n} g_{t} / t
$$

donde, $T M G=$ tasa media de germinación; $t=$ tiempo $(\mathrm{DDS}) ; g t=$ número de plántulas obtenidas en el día t.

El segundo ensayo de dosis de semilla consideró cuatro tratamientos: 1,$6 ; 3,2 ; 4,8$ y $6,4 \mathrm{~kg} \mathrm{~m}^{-2}$ de semilla seca. Las variables medidas fueron porcentaje de plantas normales (PPN) del total de semillas sembradas emergidas 10 DDS. Planta normal fue aquella con una altura de epicótilo y hoja primaria mínima de $4 \mathrm{~cm}$. Se consideró para la evaluación de dosis de semilla el tiempo de remojo de mayor germinación.

El tercer ensayo de tiempo de cosecha consideró evaluaciones a los 7, 10, 13 y 16 DDS. Las variables medidas fueron altura de plantas $(\mathrm{cm})$, conversión (peso seco de forraje, peso seco de semillas ${ }^{-1}$ ) y análisis químico: (\%) materia seca (MS), \% fibra cruda (FC), \% proteína bruta (PB), \% grasas (G) y $\%$ cenizas (C) (Nielsen, 1994). Para la evaluación de tiempo de cosecha se empleó la dosis de siembra que rindió el mayor porcentaje de plantas normales.

Cada uno de los ensayos tuvo un diseño completamente al azar con cuatro tratamientos y ocho repeticiones. Los resultados fueron analizados mediante análisis de varianza $(\mathrm{p} \leq 0,05)$. La comparación de medias se realizó a través de la prueba de rangos múltiples de Tukey $(\mathrm{p} \leq 0,05)$. Las variables medidas como porcentaje fueron sometidas, previo a análisis estadístico, a transformación según ecuación del tipo arcoseno (Ecuación 2).

$$
\sin ^{-1}(\sqrt{p})
$$

donde $p \in[0,1]$.

El análisis de la información se realizó usando el paquete computacional INFOSTAT $^{\circledR}$ (Infostat, 2007).

\section{Resultados y Discusión}

\section{Tiempo de remojo de semillas}

El tiempo de remojo afectó el porcentaje de germinación $(\mathrm{p} \leq 0,05)$ de semillas de avena en condiciones de producción de FVH (Tabla 1), siendo favorable para la germinación el remojo durante 12 horas. En general, todos los tratamientos en condición de producción experimentaron un bajo porcentaje de germinación, en relación al 92,7\% de germinación obtenido en condiciones controladas. Situación que pudo estar influenciada por la condición de clima árido de la zona, caracterizado por una amplia fluctuación térmica día/noche y baja humedad relativa (Lanino 2005, Tabla 2).

Diversas evaluaciones de germinación de avena como FVH han reportado bajos porcentajes de germinación asociados al manejo del agua de riego (volumen y frecuencia), señalando que el uso deficiente por exceso es determinante en los resultados de germinación (Bórquez et al., 1992). En este sentido, las restricciones de oxígeno en el proceso de germinación implican un atraso o paralización en el desarrollo de plantas, incluso anormalidades como ausencia de raíces (Phaneendranath, 1980).

Tanto el tratamiento de $48 \mathrm{~h}$ de remojo como el de sin remojo previo presentaron efectos similares

Tabla 1. Porcentaje de germinación y tasa media de germinación (TMG) para diferentes tiempos de remojo de semillas de avena.

\begin{tabular}{ccr}
\hline Tiempos $(\mathrm{h})$ & Germinación $(\%)$ & TMG \\
\hline 0 & $15,8 \mathrm{~b}^{\dagger}$ & $4,9 \mathrm{~b}$ \\
12 & $36,2 \mathrm{a}$ & $20,7 \mathrm{a}$ \\
24 & $35,3 \mathrm{a}$ & $19,3 \mathrm{a}$ \\
48 & $19,8 \mathrm{~b}$ & $11,4 \mathrm{~b}$ \\
\hline
\end{tabular}

$\dagger \quad$ Letras distintas indican diferencias significativas para la prueba de Tukey $(\mathrm{p} \leq 0,05)$.

Tabla 2. Promedio y rango mensual de temperaturas máximas/mínimas y humedad relativa registrada en la Estación Experimental Canchones $\uparrow$.

\begin{tabular}{lccc}
\hline Mes & Máximas $\left({ }^{\circ} \mathrm{C}\right)$ & Mínimas $\left({ }^{\circ} \mathrm{C}\right)$ & Hum. Rel. $(\%)$ \\
\hline Noviembre & $34,0(32,9-35,1)$ & $5,2(3,7-6,4)$ & $33,3(27,4-42,3)$ \\
Diciembre & $33,9(31,4-35,2)$ & $8,0(5,7-10,8)$ & $37,1(29,2-44,3)$ \\
Enero & $33,7(32,8-35,1)$ & $11,3(9,3-12,4)$ & $44,7(40,6-49,4)$ \\
\hline
\end{tabular}

$\dagger$ Datos promedio registrados durante 1995-2005 (Lanino, 2005). 
en cuanto a disminución de la germinación, evidenciando que un exceso de remojo (tratamiento de $48 \mathrm{~h}$ ) influye sobre la capacidad germinativa de semillas de avena (Phaneendranath, 1980; Less, 1983; Bórquez et al., 1992) y, por otra parte, el no remojo de semillas en una inducción retardada del proceso de germinación. No obstante, Flores et al. (2004) señalan para el caso de maíz que el remojo previo de semillas no aumenta el porcentaje de germinación respecto a semillas sin remojo.

La TMG fue afectada por los tiempos de remojo $(\mathrm{p} \leq 0,05)$, presentando tendencia similar a la evaluación del porcentaje de germinación (Tabla 1). Los resultados muestran que la mayor velocidad de germinación fue para los tratamientos de 12 y $24 \mathrm{~h}$ de remojo, siendo similar a lo indicado por FAO (2001), y Elizondo (2005), en relación al tiempo óptimo de remojo en avena. Pese a esto, Morgan et al. (1992) describieron para cebada que el remojo por $4 \mathrm{~h}$ fue suficiente para estimular la germinación.

Dado que no existieron diferencias significativas $(\mathrm{p} \leq 0,05)$ entre los tratamientos de 12 y $24 \mathrm{~h}$ de remojo, se consideró el remojo de $12 \mathrm{~h}$ como acondicionamiento óptimo para iniciar el proceso de germinación en un corto período de tiempo.

\section{Dosis de semilla}

Los valores de PPN se vieron incrementados en la medida que aumentó la dosis de semilla (Figura 1). Sin embargo, el máximo valor de PPN en el ensayo fue de $45,5 \%$, siendo esto último considerado bajo, tomando en cuenta la proporción de semillas evaluadas. En relación a ello, Bórquez et al. (1992)

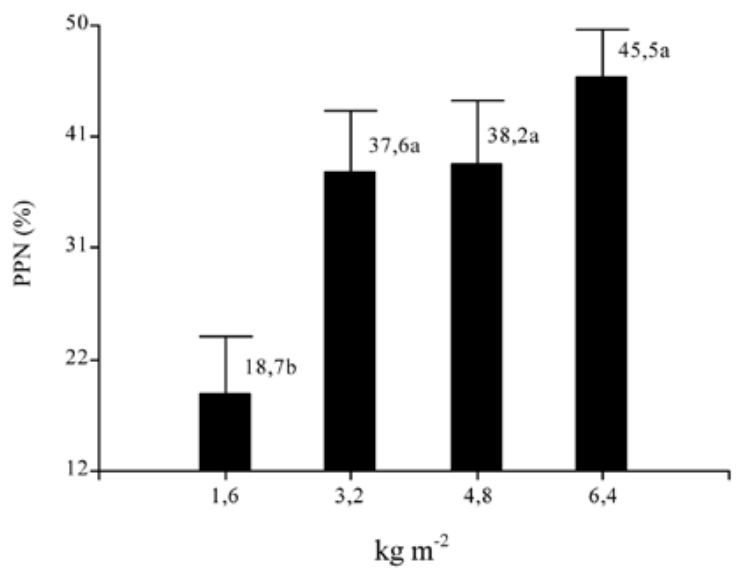

Figura 1. Porcentaje de plantas normales (PPN) a 10 DDS para 4 dosis de semillas (Letras distintas indican diferencias significativas para la prueba de Tukey $\mathrm{p} \leq 0,05$ ). reportaron un comportamiento similar en avena, agregando que cualquier dosis de siembra superior a los $3 \mathrm{~kg} \mathrm{~m}^{-2}$ representa una buena elección para un cultivo de avena como FVH.

Por su parte, el bajo PPN como respuesta en este estudio podría explicarse por las características medioambientales descritas con anterioridad, situación que influenció negativamente la germinación de semillas de avena y adicionalmente la capacidad de emergencia de plantas normales.

A partir de diversas experiencias de avena como $\mathrm{FVH}$, se pueden observar discrepancias respecto a la mejor dosis de siembra, ejemplo de ello son: 2 a $3 \mathrm{~kg} \mathrm{~m}^{-2}$ (Hidalgo, 1985), 3,9 $\mathrm{kg} \mathrm{m}^{-2}$ (Dosal, 1987) y $5,6 \mathrm{~kg} \mathrm{~m}^{-2}$ (Resh, 2001). Por este motivo se hace necesario encontrar un factor más determinante en la elección de la dosis de semilla, el cual relacione la dosis con la cantidad y calidad del forraje producido por unidad de superficie, incidiendo en ello la calidad de la semilla y las condiciones generales del manejo hidropónico. De acuerdo a los resultados de este estudio, se consideró como dosis óptima $6,4 \mathrm{~kg} \mathrm{~m}^{-2}$ de semilla, la cual obtuvo el máximo PPN. No obstante, dosis de 3,$8 ; 4,8$ y $6,4 \mathrm{~kg} \mathrm{~m}^{2}$ no presentaron diferencias significativas $(\mathrm{p} \leq 0,05)$, siendo relevante esta información al momento de establecer umbrales económicos entre dosis de semilla y rendimiento de forraje.

\section{Tiempo de cosecha}

El crecimiento de avena como FVH experimentó tres tiempos productivos, correspondientes a 7 DDS, 10 DDS y 13 DDS respectivamente. Estos tiempos mostraron diferencias en altura y producción de MS (Tabla 3), siendo característico un crecimiento inicial reducido, seguido de una fase de crecimiento vigoroso y homogéneo a los 10 DDS (Figura 2).

La cosecha 13 DDS se caracterizó por un aumento decreciente en altura cercano a los $20 \mathrm{~cm}$, al mismo tiempo experimentó una disminución en el rendimiento de MS, hojas cloróticas y tendedura de plantas. A los 16 DDS las plantas de avena presentaron síntomas de clorosis general y necrosis apical, además de la presencia de hongos entre las semillas no germinadas.

Las alturas de plantas registradas en el ensayo fueron comparativamente inferiores a lo descrito por Elizondo (2005), quien sugirió que la cosecha de FVH debe ser cuando el cultivo ha alcanzado una altura de 20-25 cm. Por otra parte, Dosal (1987) 
Tabla 3. Altura de planta, conversión (peso seco) y rendimiento de avena como FVH para distintos tiempos de cosecha.

\begin{tabular}{cccc}
\hline $\begin{array}{c}\text { Tiempo } \\
(\mathrm{d})\end{array}$ & $\begin{array}{c}\text { Altura } \\
(\mathrm{cm})\end{array}$ & $\begin{array}{c}\text { Conversión } \\
(\text { kg PS forraje kg } \\
\left.\text { PS semilla }{ }^{-1}\right)\end{array}$ & $\begin{array}{c}\text { Rendimiento } \\
\left(\mathrm{kg} \mathrm{MS} \mathrm{m}^{-2}\right)\end{array}$ \\
\hline 7 & $10,4 \mathrm{c}^{\dagger}$ & $0,80 \mathrm{a}$ & $5,01 \mathrm{~b}$ \\
10 & $16,8 \mathrm{~b}$ & $0,93 \mathrm{a}$ & $5,89 \mathrm{a}$ \\
13 & $19,3 \mathrm{a}$ & $0,76 \mathrm{a}$ & $4,59 \mathrm{~b}$ \\
16 & $19,5 \mathrm{a}$ & $0,94 \mathrm{a}$ & $5,96 \mathrm{a}$ \\
\hline
\end{tabular}

$\dagger \quad$ Letras distintas entre filas indican diferencias significativas para la prueba de Tukey $(\mathrm{p} \leq 0,05)$.

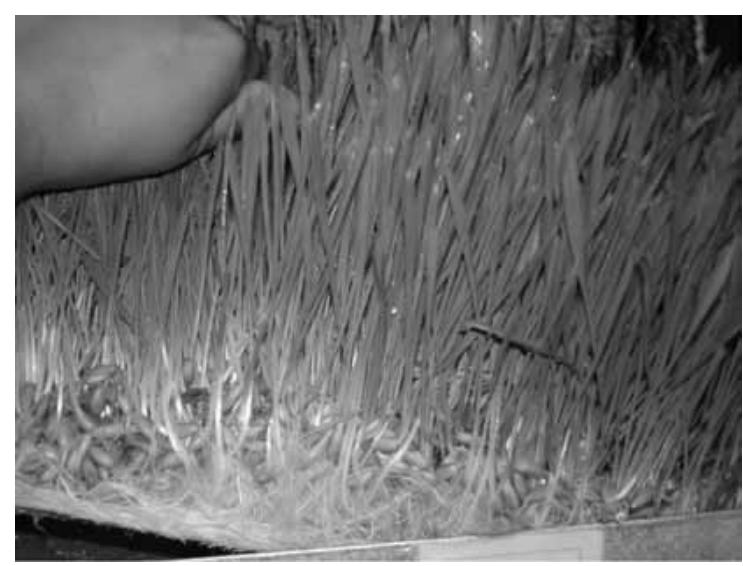

Figura 2. Crecimiento de FVH de avena a 10 DDS.

indicó períodos de 7 a $10 \mathrm{~d}$ como suficientes para completar el ciclo hidropónico de un cereal como FVH.

Los resultados de conversión obtenidos en el ensayo (Tabla 3) fueron similares a aquellos reportados por Dosal (1987), quien reportó a los 16 DDS una conversión de 0,83 , usando dosis de semilla cercana a $5 \mathrm{~kg} \mathrm{~m}^{-2}$. Las reducciones en conversión podrían explicarse por el gran desarrollo foliar experimentado por el cultivo, el cual se realizaría fundamentalmente a expensas de las reservas almacenadas en el grano (Sneath y McIntosh, 2003); $\mathrm{y}$ adicionalmente por una tasa de respiración que supera la tasa de fotosíntesis durante el desarrollo inicial (Bórquez et al., 1992).

La calidad nutritiva del FVH de avena presentó aumentos en los contenidos de MS, PB, FB y G a partir de los 7 DDS a 10 DDS (Tabla 4). Por su parte, evaluaciones realizadas a los 13 y 16 DDS no implicaron aumentos significativos ( $\mathrm{p} \leq 0,05)$ en el resto de los parámetros evaluados.

A partir del análisis químico y su comparación con otros trabajos en avena (Tabla 4), se pudo
Tabla 4. Análisis químico de FVH de avena para cuatro épocas de cosecha (100\% BMS).

\begin{tabular}{lrrrr}
\hline \multirow{2}{*}{ Componente } & \multicolumn{5}{c}{ Tiempo de cosecha (días) } \\
\cline { 2 - 5 } & \multicolumn{1}{c}{7} & \multicolumn{1}{c}{10} & 13 & 16 \\
\hline Materia seca (\%) & $31,72 \mathrm{~b}^{\dagger}$ & $36,86 \mathrm{a}$ & $35,52 \mathrm{a}$ & $37,86 \mathrm{a}$ \\
Proteína bruta (\%) & $12,78 \mathrm{~b}$ & $14,79 \mathrm{a}$ & $14,48 \mathrm{a}$ & $14,31 \mathrm{a}$ \\
Fibra cruda (\%) & $17,04 \mathrm{~b}$ & $18,77 \mathrm{a}$ & $20,01 \mathrm{a}$ & $20,58 \mathrm{a}$ \\
Grasas (\%) & $4,86 \mathrm{~b}$ & $6,65 \mathrm{a}$ & $7,76 \mathrm{a}$ & $6,30 \mathrm{a}$ \\
Cenizas (\%) & $4,59 \mathrm{a}$ & $5,11 \mathrm{a}$ & $5,39 \mathrm{a}$ & $5,75 \mathrm{a}$ \\
\hline
\end{tabular}

$\dagger$ Letras distintas entre columnas indican diferencias significativas prueba Tukey $(\mathrm{p} \leq 0,05)$.

Tabla 5. Composición química del FVH de avena para diferentes épocas de cosecha obtenidos por diferentes autores.

\begin{tabular}{lccccc}
\hline \multirow{2}{*}{ Componente } & \multicolumn{5}{c}{ Tiempo de cosecha (días) } \\
\cline { 2 - 6 } & $8^{\dagger}$ & $11^{\ddagger}$ & $12^{\dagger}$ & $15^{¥}$ & $20^{£}$ \\
\hline Materia seca (\%) & - & 27,2 & - & 15,5 & 20,1 \\
Proteína bruta (\%) & 13,1 & 10,4 & 14,7 & 15,6 & 17,2 \\
Fibra cruda (\%) & - & - & - & - & 23,9 \\
Cenizas (\%) & - & 3,6 & - & 2,5 & 6,3 \\
\hline
\end{tabular}

\footnotetext{
$\dagger$ Bravo (1988)

${ }^{¥}$ Dosal (1987)

${ }^{£}$ Hidalgo (1985)
}

observar que el contenido de MS fue superior a aquellos reportados por Dosal (1987) e Hidalgo (1985), quienes reportaron una tendencia a la disminución de la MS a medida que transcurrieron los DDS del cultivo.

En cuanto a PB, se observaron diferencias en su contenido entre las dos primeras etapas del cultivo, representando un patrón característico en avena según diversos estudios (Tabla 5). El marcado aumento de la PB según Sneath y McIntosh (2003) estaría relacionado con la concentración de proteínas por efecto de la pérdida de biomasa experimentada por el cultivo.

A partir de estos resultados se puede señalar que la calidad nutritiva de avena como FVH es considerada buena por su contenido de proteínas (13-14\%), la cual es suficiente para satisfacer requerimientos de diversos tipos de ganado (López et al., 2009). Tendencia similar presentaron las variables de FB y $\mathrm{G}$, las cuales aumentaron al mismo tiempo que avanzó el tiempo de cosecha, presentando valores en general inferiores a los reportados por Hidalgo (1985) para FB (Tabla 5).

El contenido de $\mathrm{C}$ para los distintos tiempos de cosecha no presentaron diferencias significativas 
$(\mathrm{p} \leq 0,05)$, siendo estos intermedios según lo reportado por Hidalgo (1985) y Dosal (1987).

Finalmente, períodos de 10 DDS serían suficientes para completar el ciclo de producción de FVH en avena. Ciclos más largos no son convenientes, debido a la pérdida de calidad sanitaria del material cosechado.

\section{Conclusiones}

A partir de los resultados obtenidos en este estudio se pudieron establecer los parámetros productivos y nutritivos básicos para el cultivo de avena como $\mathrm{FVH}$ en condiciones de desierto, consistentes en un tiempo de remojo de semillas de $12 \mathrm{~h}$, una dosis de siembra de $6,4 \mathrm{~kg} \mathrm{~m}^{-2}$ y una duración de ciclo de cultivo de 10 DDS, en cuyo momento el forraje presentó un valor nutritivo de $14,79 \%$ de $\mathrm{PB}, 6,65 \%$ de $\mathrm{G}$ y $18,77 \%$ FC, al mismo tiempo de presentar buen vigor y estado sanitario.

\section{Agradecimientos}

A la Dirección General de Investigación de la Universidad Arturo Prat, quien financió el estudio a través del proyecto DI0002-06. A la académica Ing. en Alimentos Sra. María I. Oliva E. por su colaboración en el uso de instrumental de Laboratorio de Tecnología de los Alimentos-UNAP.

\section{Literatura Citada}

Bórquez, F.; Figueroa, M.; Parilo, J.; Tima, M. e Hidalgo, R. 1992 Producción de forraje en condiciones de hidroponía. I. Tiempo de hidratación, dosis de semilla y fertilización de avena y triticale. Revista Agrociencia 8(1): 11-20.

Bravo, M.

1988 Niveles de avena hidropónica en la alimentación de conejos angora. Universidad de Concepción, Facultad de Ciencias Agropecuarias y Forestales. Departamento de agronomía. Chillán. Chile. 73 p.

Carevic, A.

2000 Los campesinos del desierto chileno. Universidad Arturo Prat. Departamento de Agricultura del Desierto. Iquique, Chile. 222 p.

Chang, M.; Hoyos, M.; Rodríguez, A. 2000 Producción de Forraje Verde Hidropónico. Centro de Investigación de Hidroponía y Nutrición Mineral. Lima, Perú. Disponible en: http://www.rlc.fao.org/prior/segalim/ pdf/4 [Consultado en Julio 2010].

Dosal, J.

1987 Efecto de la dosis de siembra, época de cosecha y fertilización sobre la calidad y cantidad de forraje de avena producido bajo condiciones de hidroponía. Universidad de Concepción, Facultad de Ciencias Agropecuarias y Forestales. $106 \mathrm{p}$.

Elizondo, J.

2005 Forraje verde hidropónico: una alternativa para la alimentación animal. Revista ECAG 32: 36-39.

FAO (Organización de las Naciones Unidas para la Agricultura y la Alimentación).

2001 Manual Técnico Forraje Verde Hidropónico. Oficina Regional de la FAO para América Latina y el Caribe. 70 p.

Figueroa, M.; Bórquez, F.; Tima, M.; Leighton, P.

1999 Condiciones ambientales y uso de solución nitrogenada en producción de forraje "hidropónico" de avena (Avena sativa L.) en invernadero. Revista Agrociencia 15(2): 195-206.
Flores, Z.; Urdaneta, G.; Manzano M.

2004 Potencialidad de diversos cultivares de maíz (Zea mays) para producir forraje verde hidropónico. Pastos y forrajes. In: XII Congreso Venezolano de Producción e Industria Animal. Pp. 135

Fuentes, F.

2009 Recursos forrajeros para la alimentación de ganado caprino, bajo las condiciones de la Pampa del Tamarugal. In: Estudio básico: Investigación silvoagropecuaria de innovación de la I Región. Tapia F. (ed.). Santiago, Chile. Instituto de Investigaciones Agropecuarias (Ed). Boletín INIA No $197:$ 110-115.

Habit, M.

1981 Prosopis tamarugo: Arbusto Forrajero para Zonas Aridas. Estudio FAO: Producción y protección vegetal. $\mathrm{N}^{\mathrm{o}} 25,143 \mathrm{p}$.

Hidalgo, $\mathrm{L}$

1985 Producción de forraje en condiciones de hidroponía. I. Evaluaciones preliminares en avena y triticale. Universidad de Concepción, Facultad de Ciencias Agropecuarias y Forestales. $64 \mathrm{p}$.

INE

2007 Censo agropecuario y forestal 2007. Disponible en: http://www.ine.cl/canales/chile_estadistico/censos_agropecuarios/censo_agropecuario_07_comunas.php [Consultado en Agosto 2010]

INFOSTAT

2007 InfoStat versión 2007. Grupo InfoStat, FCA, Universidad Nacional de Córdoba, Argentina.

Lanino, $\mathrm{M}$.

2005 Antecedentes climáticos de la Estación Experimental Canchones, en la Pampa del Tamarugal. Revista de Agricultura del Desierto 3:1-24.

Less, $\mathrm{P}$.

1983 Ganadería Hidropónica. Agricultura de las Américas. 32(10): 16-41. 
López, R.; Murillo, B.; Rodríguez, G.

2009 El forraje verde hidropónico (FVH): Una alternativa de producción de alimento para el ganado en zonas áridas. Interciencia 34(1): 121-126.

Morales, M.; Fuente, B.; Juárez, M.; Ávila, E.

2009 Effect of substituting hydroponic green barley forage for a commercial feed on performance of growing rabbits. World Rabbit Science. 17 (1).

Morgan, J.; Hunter, R.; O’Haire, R.

1992 Limiting factors in hydroponic barley grass production. In: Proceedings of the 8th International Congress on Soilless Culture. Netherland. pp: 241-261.

Müller, L.; Souza, O.; Manfron, P.; Petter, S.; Haut, V.; Dourado, D.; Lemos, N.; Camacho, D.

2006 Forragem hidropônica de milheto: produção e qualidade nutricional em diferentes densidades de semeadura e idades de colheita. Ciencia Rural, Santa Maria 36(4): 1094-1099.

Nielsen, S.

1994 Introduction to the Chemical Analysis of Foods. Ed. Jones and Bartlett Publishers. U.S.A. pp: 209-212.

Phaneendranath, B.

1980 Influence of amount of water in the paper towel on standard germination test. J. Seed Technol. 5(2): 82-87.

Resh, H.

2001 Cultivos Hidropónicos: Nuevas Técnicas de Producción. Editorial Mundi Prensa. España. 558 p.
Riveros, F.

1991 The Genus Prosopis and its potential to improve livestock production in Arid and semiarid Regions". Prosopis Species Aspects of their Value, Research and Development-CORD. pp: 237-248.

Rodríguez, C.; Rodríguez, H.; Ruiz, O.; Flores, A.; Grado, J.; Arzola, C.

2005 Use of green fodder produced in hydroponics systems as supplement for salers lactating cows during the dry season. Proc. Western Section, Am. So. Anim. Sci. 56: 271-274.

Rojas, R.; Batelaan, O.; Feyen, L.; Dassargues, A. 2009 Assessment of conceptual model uncertainty for the regional aquifer Pampa del Tamarugal - North Chile. Hydrol. Earth Syst. Sci. Discuss. 6: 5881-5935.

Salisbury, F.; Ross, C.

2000 Fisiología Vegetal. Madrid, España. Thomson Editores, Spain Paraninfo. 988 p.

Sneath, R.; Macintosh, F.

2003 Review of Hydroponic Fodder Production for Beef Cattle. Meat \& Livestock Australia Limited. 54 p.

Torres, $\mathrm{H}$

1989 The Pampa del Tamarugal National Reserve: rehabilitation of a fodder tree forest in the desert of Atacama in Chile. FAO Conservation guide 21, Food and Agriculture Organization of the United Nations. Rome, Italy. 